\title{
ROBUST TRIMORPH BULK SMA MICROACTUATORS FOR BATCH MANUFACTURING AND INTEGRATION
}

\author{
Stefan Braun ${ }^{1}$, Thomas Grund ${ }^{2}$, Sveinbjörg Ingvarsdottír ${ }^{1}$, \\ Wouter van der Wijngaart ${ }^{1}$, Manfred Kohl ${ }^{2}$ and Göran Stemme ${ }^{1}$ \\ ${ }^{1}$ Microsystem Technology Lab, School of Electrical Engineering \\ KTH-Royal Institute of Technology, Stockholm, Sweden \\ ${ }^{2}$ Forschungszentrum Karlsruhe $\mathrm{GmbH}$ \\ Institut für Mikrostrukturtechnik, Karlsruhe, Germany
}

\begin{abstract}
This paper introduces the concept of batch microfabrication and electrical contacting of bulk SMA microactuators. This concept addresses technical solutions for the main challenges related to using SMA actuators such as the necessary mechanical bias force, the difficult electrical contacting and the high power needed for actuation. We report on initial SMA-dielectric-metal trimorph test structures and their characteristics. The bias force is provided by a dielectric layer and the electrical contacting of the bulk SMA is avoided using indirect electrical heating via an additional metal layer. Three mm long beams can provide several hundreds of $\mu \mathrm{N}$ and deflect several hundreds of $\mu \mathrm{m}$. The actuation power is reduced approx. 2.5 times compared to direct heating schemes.
\end{abstract}

Keywords: SMA, microactuators.

\section{INTRODUCTION}

Shape Memory Alloys (SMA) are promising actuator materials because of their high energy density, exceeding that of other actuation principles by at least an order of magnitude [1]. SMA can be easily plastically deformed in the cold state and recovers its initial shape when heated above its conversion temperature. This process is reversible, however, a biasing force is needed to deform the SMA element in the cold state (cold-state reset).

SMA is mostly actuated using direct resistive heating, implicating several drawbacks. The SMA forms a stable native oxide which makes electrical

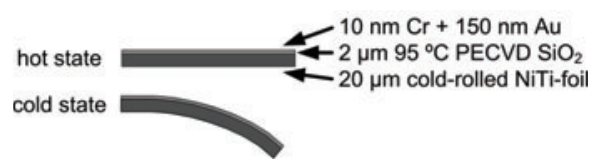

Fig. 1 Cross-sectional schematic of the trimorph. The pure bulk SMA sheet is flat in the hot state. During operation, the layer stress deforms the trimorph in the cold state and heating the sample flattens the trimorph. contacting difficult. Moreover, the power consumption is relatively high [1].

There are different approaches for integrating SMA material in MEMS devices. First, one can fabricate the SMA microactuators separately prior to integration with the microstructures and provide the cold-state reset by incorporating a mechanical obstruction, pre-stressing the SMA element [2]. Machining the bulk SMA element separately features specific advantages, such as the availability of NiTi-foils in a wide thickness range and with reproducible bulk material characteristics. This allows for adjustable mechanical robustness and reduced material costs. However, the required per-

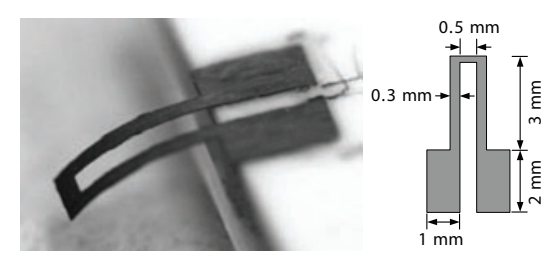

Fig. 2 (left) Photograph of a SMA/SiO $\mathrm{S}_{2} / \mathrm{AU}$ $(20 / 2 / 0.15 \mu \mathrm{m})$ trimorph test device in the cold state and (right) the geometry of the beam. 
Table 1 The deflection of the tips of the beams inbetween the different fabrication steps.

\begin{tabular}{ccccc}
\hline \hline sample & $\mathrm{SiO}_{2}$ deposition conditions & pure SMA & after $\mathrm{SiO}_{2}$ deposition & after Cr/Au deposition \\
\hline 1 & $1 \mu \mathrm{miO}_{2} @ 90^{\circ} \mathrm{C}$ & $120 \mu \mathrm{m}$ & $330 \mu \mathrm{m}$ & $-60 \mu \mathrm{m}$ \\
2 & $1 \mu \mathrm{m} \mathrm{SiO} \mathrm{m}_{2} @ 90^{\circ} \mathrm{C}$ & $35 \mu \mathrm{m}$ & $420 \mu \mathrm{m}$ & $200 \mu \mathrm{m}$ \\
3 & $1 \mu \mathrm{SiO}_{2} @ 90^{\circ} \mathrm{C}$ & $55 \mu \mathrm{m}$ & $420 \mu \mathrm{m}$ & $300 \mu \mathrm{m}$ \\
4 & $2 \mu \mathrm{m} \mathrm{SiO}_{2} @ 90^{\circ} \mathrm{C}$ & $75 \mu \mathrm{m}$ & $360 \mu \mathrm{m}$ & $260 \mu \mathrm{m}$ \\
5 & $2 \mu \mathrm{m} \mathrm{SiO}_{2} @ 90^{\circ} \mathrm{C}$ & $55 \mu \mathrm{m}$ & $850 \mu \mathrm{m}$ & $450 \mu \mathrm{m}$ \\
6 & $2 \mu \mathrm{m} \mathrm{SiO}_{2} @ 90^{\circ} \mathrm{C}$ & $-85 \mu \mathrm{m}$ & $1220 \mu \mathrm{m}$ & $450 \mu \mathrm{m}$ \\
7 & $1 \mu \mathrm{miO}_{2} @ 200^{\circ} \mathrm{C}$ & $60 \mu \mathrm{m}$ & $960 \mu \mathrm{m}$ & $900 \mu \mathrm{m}$ \\
8 & $2 \mu \mathrm{miO}_{2} @ 95^{\circ} \mathrm{C}$ & $270 \mu \mathrm{m}$ & - & $920 \mu \mathrm{m}$ \\
9 & $2 \mu \mathrm{m} \mathrm{SiO}_{2} @ 95^{\circ} \mathrm{C}$ & $180 \mu \mathrm{m}$ & - & $500 \mu \mathrm{m}$ \\
\hline \hline
\end{tabular}

component assembly with microstructures is not batch compatible and results in unacceptable high costs.

A second approach, sputtering of thin SMA films [3], allows for batch actuator integration. In this case, the cold-state reset is provided by the built-in film stress. However, sputtering of SMA is complicated and demands a high-temperature annealing of the deposited layer. Furthermore, the film thickness and therewith the mechanical performance of the SMA is limited.

This paper presents a concept of batch microfabrication of trimorph bulk SMA microactuators.

\section{TRIMORPH SMA MICROACTUATORS}

There are two main technical challenges to be addressed to allow for batch integration of bulk SMA microactuators. The first is to provide a batch manufacturing compatible cold-state reset mechanism; the second is to allow batch manufacturing compatible electrical contacting.

In this work we have adapted the thin film stressinduced cold-state reset method to deform bulk SMA foil by adding a dielectric layer at an elevated temperature on top of the SMA sheet. The dielectric layer stress deforms the actuator in the coldstate. This built-in cold-state reset eliminates the need for mechanical pre-tensioning or additional microsprings. The choice of dielectric material, deposition conditions, layer thickness and thermal treatment [4] allows for tuning the actuator characteristics.
For the heating we opt for an indirect heating scheme, in which a thin metal layer is positioned on top of the oxide. The heater is electrically isolated from the SMA and allows for uncomplicated electrical contacting and low actuation current. Moreover, the heater can be patterned for optimized heat transfer, reducing thermal gradients along the beam and reducing power consumption.

The electrical contacting and the intrinsic coldstate reset are the key enablers for batch processing. Three key actuator performance factors, i.e. the shape memory effect, the cold-state reset and the electrical heating, can be optimized independently

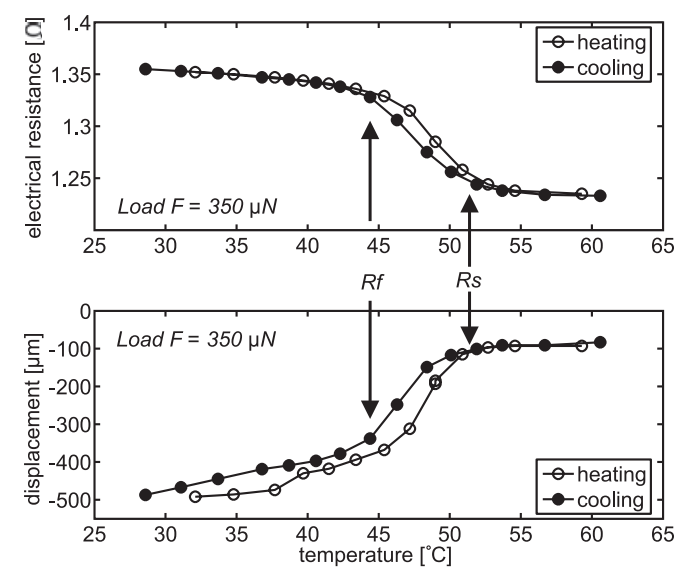

Fig. 3 The bulk material characteristics are evaluated by measuring the temperature-electrical resistance (top) and temperature-displacement (bottom) characteristics of a pure NiTi beam under $350 \mu N$ fixed load. $T_{R, s}$ and $T_{R, f}$ denote the start and finish rhombohedral phase transformation temperatures, respectively. 


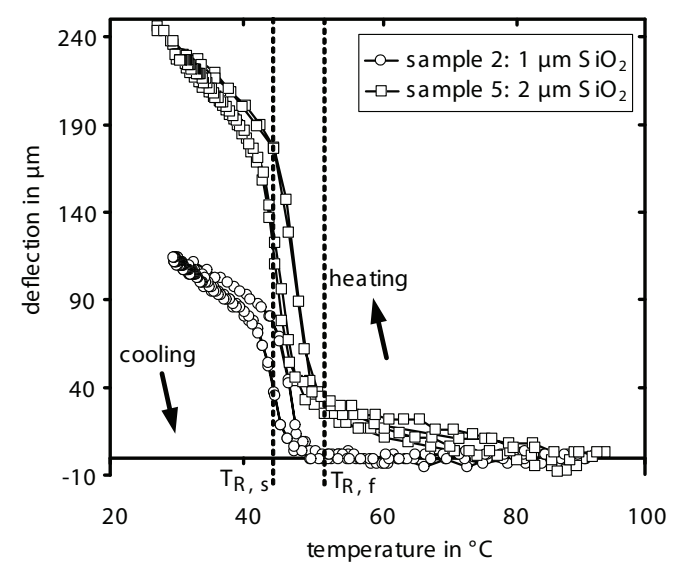

Fig. 4 Temperature-deflection characteristics of samples 2 and 5.

by each respective trimorph layer.

Note that in an alternative scheme a very thin dielectric layer, causing negligible mechanical deformation but providing electrical isolation, could be combined with a thick metal layer for both heating and mechanical deformation. Such a trimorph scheme further increases the practical tuning range of the actuators.

\section{TEST DEVICE FABRICATION}

A $20 \mu \mathrm{m}$ thick cold-rolled Ti-49at.\%Ni alloy foil is used as base material for the microactuators. The material is heat treated at $450{ }^{\circ} \mathrm{C}$ for $30 \mathrm{~min}$ in its flat position to allow for the one-way shape memory effect. Above room temperature the material shows the rhombohedral phase transformation which is characterized by a narrow hysteresis of a few ${ }^{\circ} \mathrm{C}$.

For comparison with direct electrical heating, the SMA microactuators are designed as U-shaped beams. After fixing the foil material on a substrate using an adhesive, the beams are lithographically patterned and wet etched. The actuators are subsequently released by sacrificial etching of the adhesive, and finally bonded to a ceramic substrate using heat conductive glue.

Thereafter, $\mathrm{SiO}_{2}$ is PECVD deposited ( 1 and $2 \mu \mathrm{m})$ at elevated temperatures $\left(90^{\circ} \mathrm{C}\right.$ and $\left.200{ }^{\circ} \mathrm{C}\right)$. Finally, a $10 / 150 \mathrm{~nm}$ thick $\mathrm{Cr} / \mathrm{Au}$ layer is evaporated on top of the oxide.

Table 1 overviews the different fabrication pa- rameter combinations and the beam deflections measured inbetween the different fabrication steps.

Fig. 2 shows a photograph of a deflected test device in the cold state.

\section{EVALUATION OF THE TEST DEVICES}

Due to the limited thickness of the top metal layer, the stress in the dielectric layer determines the cold state deflection to a large extent. The stress is a combination of thermal stress, caused by the difference between the film deposition temperature and operational temperature, and the intrinsic stress. A back-of-the-envelope estimation shows that thermal and intrinsic stress levels in our test devices should have the same magnitude order. Table 1 shows a large deviation in deflection between different samples with equal manufacturing schemes. These are partly contributed to variations in the dielectric deposition conditions and initial stresses of the SMA bulk material. Also, the large change in deflection after the metal deposition cannot be contributed to the stress caused by the metal only. Potentially, the large beam deflections induce plastic deformation. These effects are subject to further investigation.

Fig. 3 shows measured electrical resistance and temperature-displacement characteristics from the original SMA bulk material. These experiments were carried out in a thermostat under quasi-static conditions using a video microscope and with the

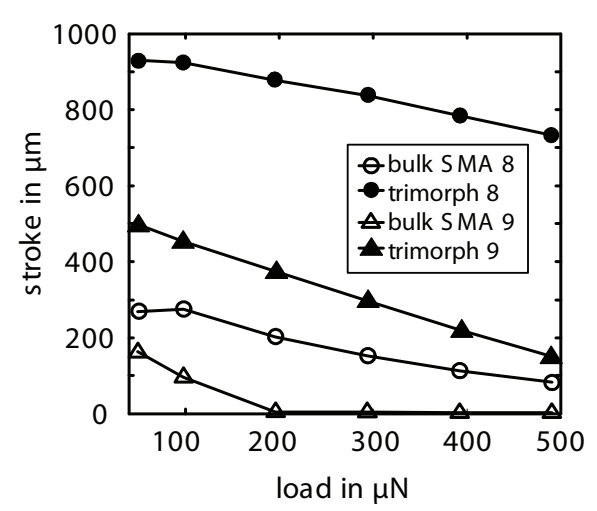

Fig. 5 Measurements of the cold-state deflection of samples 8 and 9 under varying load, before (bulk SMA) and after the oxide/metal deposition (trimorph). 


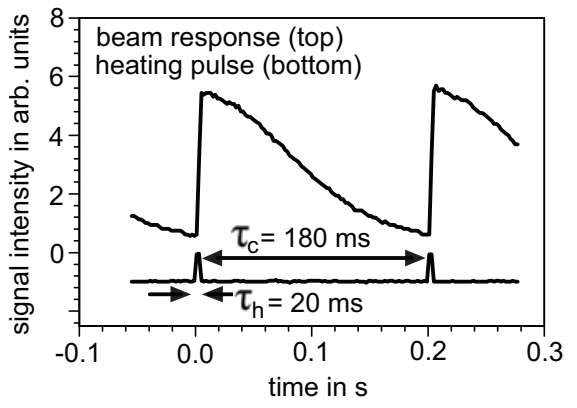

Fig. 6 Dynamic deflection measurements.

four point resistance measurement method. External loads are applied by microweights. The rhombohedral phase transformation starts at the temperature $\mathrm{T}_{R, s}=44{ }^{\circ} \mathrm{C}$ and stops at $\mathrm{T}_{R, f}=51{ }^{\circ} \mathrm{C}$.

The temperature-deflection characteristics of sample 2 and 5 (cf. table 1) for zero mechanical load are plotted in Fig. 4. Three operational regions can be clearly distinguished. For temperatures below $\mathrm{T}_{R, s}$ the structure behaves quasi plastically due to the martensitic state. For temperatures between $\mathrm{T}_{R, s}$ and $\mathrm{T}_{R, f}$ the shape recovery effect nearly flattens the beam. For temperatures above $\mathrm{T}_{R, f}$ the structure behaves as a pure thermal bimorph characterized by the Young's moduli of each layer. Sample 5 clearly exhibits a much larger temperature-deflection dependency than sample 2 due to its thicker oxide layer. At $90^{\circ} \mathrm{C}$, which is the $\mathrm{SiO}_{2}$ deposition temperature, both beams are flat.

Mechanical force measurements (Fig. 5) show a considerable stroke and work output of the actuators. Fig. 6 shows the dynamic characterization with a laser and a position sensing detector. Typical time constants are $\tau_{h}=20 \mathrm{~ms}$ for heating and $\tau_{c}=180 \mathrm{~ms}$ for cooling. Thus, the maximum operation frequency is $5 \mathrm{~Hz}$, mainly limited by the heat transfer time upon cooling.

The reference sample consumed $245 \mathrm{~mW}$ for a $70 \mathrm{~ms}$ heat pulse duration and the trimorph beam only $91 \mathrm{~mW}$ for a $67 \mathrm{~ms}$ pulse duration. Thus, indirect heating requires approximately a factor 2.5 less power than direct heating. This advantage is due to the selective heat of the mechanically active regions of the beams, which are located along the beam surface in the case of bending actuators. Thus, by the design of the metal layer, the heat can be locally concentrated and the required energy can be optimized.

\section{CONCLUSION}

This paper presents a concept for batch microfabrication and electrical contacting of bulk SMA microactuators, investigating technical solutions for issues of SMA actuators. The necessary mechanical bias force is provided by a $\mathrm{SiO}_{2}$ layer, which is deposited at elevated temperatures and stress-deforms the SMA element in the cold state. The difficult electrical contacting of the SMA material is avoided utilizing indirect resistive heating through a thin metal layer on top of the $\mathrm{SiO}_{2}$ layer. First test structures were fabricated and evaluated. Three mm long beams can provide several hundreds of $\mu \mathrm{N}$ and deflect several hundreds of $\mu \mathrm{m}$. The test structures consumed $91 \mathrm{~mW}$, which is approx. 2.5 times less compared to direct heating of the pure SMA microactuator.

\section{ACKNOWLEDGEMENTS}

This work is part of the Q2M project and receives research funding from the European Commission through the sixth framework program.

\section{REFERENCES}

[1] M. Kohl, Shape Memory Microactuators. Springer, 2004.

[2] K. Skrobanek, M. Kohl, and S. Miyazaki, "Stress-optimised shape memory microvalves," in Micro Electro Mechanical Systems, 1997. MEMS '97, Proceedings, IEEE., Tenth Annual International Workshop on, 1997, pp. 256-261.

[3] P. Krulevitch, A. Lee, P. Ramsey, J. Trevino, J. Hamilton, and M. Northrup, "Thin film shape memory alloy microactuators," Journal of Microelectromechanical Systems, vol. 5, no. 4, pp. 270 - 82, December 1996.

[4] Z. Cao and X. Zhang, "Mechanism of temperature-induced plastic deformation of amorphous dielectric films for mems applications," in Proceedings of the 18th IEEE International Conference on Micro Electro Mechanical Systems (MEMS), 2005, pp. 471-474. 